\section{Carlos Plaza}

Españoles en la corte de los Medici.

Arquitectura y política en tiempos de Cosimo I

565 págs. Madrid

Centro de Estudios

Europa Hispánica, 2016

ISBN 978-84-1524-556-8

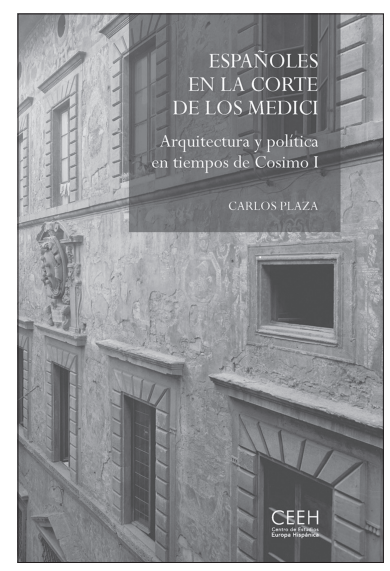

\section{Francisco MERINo RodrígueZ*}

$\mathrm{A}$ quellos que teníamos noticias de la trayectoria docente e investigadora del profesor Carlos Plaza esperábamos con no poca impaciencia la publicación del libro que ahora sostenemos en nuestras manos, Españoles en la corte de los Medici. Arquitectura y política en tiempos de Cosimo I, cuyo origen se encuentra en la tesis doctoral del autor, codirigida por los profesores Ana Marín Fidalgo, de la Universidad de Sevilla, y Amadeo Belluzi, de la Università degli Studi di Firenze, y que fue defendida públicamente en 2013 en la Escuela de Arquitectura de la Universidad de Sevilla. Con el paso del tiempo, esta expectación ha ido in crescen$d o$, alimentada por unas publicaciones previas ${ }^{1}$ en las cuales el autor anticipó algunas de las líneas maestras de esta investigación, al tiempo que se esbozaban algunos resultados y conclusiones. No obstante, estos primeros escritos no desvelaban el verdadero alcance de este trabajo, sus dimensiones y su rotundidad.

* Este trabajo se enmarca en el proyecto de investigación ACAF/ ART IV «Cartografías analíticas, críticas y selectivas del entorno artístico y monumental del área mediterránea en la edad moderna» (HAR2015-66579-P), financiado por el Ministerio de Economía y Competitividad.

1. Plaza, C., "Arquitectura y mecenazgo artístico de la comunidad española en la Florencia del Quinientos» en BARRAL, M.D.; FerNándeZ Castiñeiras, E.; Fernández RodrígueZ, B.; Monterroso Montero, J.M. (eds.), Mirando a Clío. El arte español reflejo de su historia, actas del XVIII Congreso Nacional de Historia del Arte, 20-24 de septiembre de 2010, Santiago de Compostela. Santiago de Compostela: Universidade de Santiago de Compostela, 2012, págs. 15381551; idem, «Arquitectura militar en Italia en el siglo XVI y la aportación española: el caso de Florencia y Siena», en HuERTA, S. (ed.), Actas del VII Congreso Nacional de Historia de la Construcción. Madrid: Instituto Juan de Herrera, Sociedad Española de Historia de la Construcción, 2011, págs. 1133-1146; idem, “"Davitte Fortini Architettore” y la construcción de los edificios de la Orden de Caballeros de Santo Stefano en Pisa (1562-1572)», Quaderni Stefaniani, 31, 2013, págs. 129152; idem, «Renovatio urbis: arquitectura, ciudad y poder hispánico en Milán, Nápoles y Palermo entre Carlos Vy Felipe II», en MínguEZ, V. (ed.), Las artes y la arquitectura del poder, actas del XIX Congreso Nacional de Historia del Arte, 5-8 de septiembre de 2012, Universitat Jaume I, Castellón de la Plana. Castellón de la Plana: Publicaciones de la Universitat Jaume I, 2013, págs. 1169-1185.
Como bien indica el autor, el estudio de las relaciones entre España e Italia ha sido un campo muy provechoso en los últimos años, en un principio alentado por las celebraciones de los centenarios de Carlos Vy Felipe II, que dieron lugar a estudios que ampliaban la visión del Imperio y de la Monarquía Hispánica. Posteriormente salieron a la luz otros, centrados en analizar la presencia española en la península itálica, a los que se unieron un conjunto de publicaciones sobre los vínculos diplomáticos entre España e Italia, que con el paso del tiempo han adquirido un carácter más transversal, al incluir otras áreas, como la economía, la administración, la religión, la sociedad, la cultura y el arte. ${ }^{2}$ No obstante, en lo concerniente a las relaciones artísticas y culturales, son muy relevantes los estudios que analizan los vínculos con Génova, ${ }^{3}$ Nápoles, ${ }^{4}$ Bolonia ${ }^{5}$ y Calabria, ${ }^{6}$ así como el estrecho trato con Roma. ${ }^{7}$ Igualmente, a este panorama plural habría que añadir la reciente tesis doctoral de Sara Caredda sobre el patronazgo artístico español en la Cerdeña barroca. ${ }^{8}$

Junto a las investigaciones anteriores también se encuentran otras, ya clásicas, de Fernando Marías, George Kubler, Earl E. Rosenthal, Manfredo Tafuri, Howard Burns o Cristiano Tessari, que se centran en las conexiones de España con Italia y en la presencia de la primera en la segunda. A estas obras habría que adjuntar, con un carácter más general, las de Benedetto Croce y Michael Cole, o la reciente publicación de Piers Baker-Bates y Miles Pattenden. ${ }^{9}$ No obstante, a pesar de este amplio panorama de estudios, Carlos Plaza subraya que «las relaciones entre España y Florencia durante el Renacimiento no han sido analizadas en profundidad, sobre todo por lo que se refiere a aspectos históricos y artísticos», si bien puntualiza que todas estas cuestiones no entraban en los objetivos plan-

2. En relación con los estudios sobre los vínculos diplomáticos entre España e Italia y desde una perspectiva más transversal, en los últimos tiempos se ha abierto otra vía de investigación centrada en el papel que jugaron los embajadores culturales y en el intercambio de regalos; véase VISCEGLIA, M.A., (coord.), Diplomazia e politica della Spagna a Roma: figure di ambasciatori. Roma: Università degli Studi Roma Tre, 2008; idem, Roma papale e Spagna. Diplomatici, nobili e religiosi tra due corti. Roma: Bulzoni, 2010; BERNSTORFF, M. VON; KUBERSKY-PIREDDA, S., (coords.), L'arte del dono: scambi artistici e diplomazia tra Italia e Spagna, 1550-1650. Cinisello Balsamo, Milán: Silvana, 2013; y VolPINI, P., Los Medici y España. Príncipes, embajadores y agentes en la Edad Moderna. Madrid: Sílex, 2017.

3. BocCARDo, P.; Colomer, J.L.; FABIO, C. DI (dirs.), España y Génova. Obras, artistas y coleccionistas. Madrid: Centro de Estudios Europa Hispánica, 2003.

4. Colomer, J.L., España y Nápoles. Coleccionismo y mecenazgo virreinales en el siglo XVII. Madrid: Centro de Estudios Europa Hispánica, 2009.

5. Colomer, J.L.; Serra, A. (dirs.), España y Bolonia. Siete siglos de relaciones artísticas y culturales. Madrid: Centro de Estudios Europa Hispánica, 2006.

6. Anselmi, A. (ed.), La Calabria del viceregno spagnolo. Storia, arte, architettura e urbanistica. Roma: Gangemi, 2009.

7. Idem (ed.), I rapporti tra Roma e Madrid nei secoli XVI e XVII: arte, diplomazia e politica. Roma: Gangemi, 2014.

8. CAREDDA, S., El patronazgo español en la Cerdeña barroca: arte, poder y devoción, tesis doctoral. Facultad de Geografía e Historia, Universitat de Barcelona, 2016.

9. Baker-Bates, P.; Pattenden, M. (eds.), The Spanish Presence in Sixteenth-Century Italy. Images of Iberia. Burlington: Ashgate, 2015. 
teados para su escrito. ${ }^{10}$ Sin embargo, entendemos que pueden configurarse como una línea de investigación abierta que tal vez en un futuro podría aportar nuevos elementos discursivos y de análisis.

La obra se estructura en dos partes claramente definidas. En la primera se analizan las relaciones entre la Monarquía Hispánica y Florencia durante el siglo XVI, mientras que la segunda se centra en la comitencia española en la ciudad del Arno. A su vez, la primera parte se articula en tres capítulos. El primero de ellos, «La alianza política de los Medici con España en los tiempos de Carlos Vy Felipe II», se dedica a las vinculaciones entre España y Florencia durante la centuria del Quinientos. Carlos Plaza nos ofrece un relato de la compleja situación política italiana de todo este período, poniendo una especial atención en las primeras décadas del siglo hasta la creación del Ducado de Florencia en 1531. Sin esta aportación no se podría llegar a comprender en toda su dimensión el papel que desde el punto de vista político y geoestratégico desempeñó Florencia en el difícil equilibrio de fuerzas entre el Papado, Francia y España, con estas dos últimas como rivales por controlar no solo la península itálica, sino también el Mediterráneo occidental. Desde un punto de vista más local y centrado en el día a día de la ciudad toscana, este enfrentamiento y estos intereses contrapuestos tuvieron su reflejo en la presencia de dos grupos, uno favorable a los franceses, y otro, integrado por la familia Medici, a la Monarquía Hispánica. Al mismo tiempo, ambos grupos se enfrentaban por el control de la ciudad y la forma de dirigirla. El fiel de la balanza terminó inclinándose hacia la familia Medici, que, bajo los auspicios del emperador Carlos V, se situó nuevamente al frente del gobierno de la ciudad.

El papel de Cosimo I en la consolidación del ducado florentino fue fundamental, pero en esa tarea no lo fue menos la figura del virrey español en Nápoles, Pedro de Toledo, y el resto de su familia, sobre todo su hija, y futura esposa de Cosimo, Eleonora. A lo largo de todo el texto el autor incide en la buena sintonía entre Cosimo y el virrey, con quien llegó a fraguar una relación con tintes casi paternofiliales. Sin embargo, esta relación fue especialmente beneficiosa para Cosimo, pues la familia Álvarez de Toledo le proporcionó un ingente caudal de información y de experiencia que aplicó, por un lado, a la configuración de la nueva estructura política y administrativa del ducado florentino y, por otro, a la creación de un entorno y aparato áulico, del cual no había experiencias previas debido al pasado republicano de la ciudad.

La relación entre los Medici y los Álvarez de Toledo no se circunscribió a aquellos aspectos relacionados con la creación de las estructuras políticas y administrativas del ducado mediceo, sino que se expandió a todas las áreas, incluidas las artes, y Plaza nos informa de que durante este período se creó una fecunda y fructífera circulación de ideas y personas entre Florencia, Nápoles y las posesiones hispanas de los Álvarez de Toledo. El autor ejemplifica esta circunstancia con la difusión entre estos centros de la tipología arquitectónica del jardín escultórico, en la que los hijos del virrey,

10. Plaza, C., Españoles en la corte de los Medici..., págs. 22 y 23.
García y Luis de Toledo, jugaron un papel fundamental. Según concluye, las residencias napolitanas de ambos, la villa y el jardín de Chiaia - perteneciente a García de Toledo-y la villa de Pizzofalcone - propiedad de Luis de Toledo- se convierten en hitos tipológicos, cuyas experiencias se exportarán al ducado mediceo, y tendrán eco en la creación del jardín de Boboli por parte de la esposa del duque, Eleonora de Toledo. La relación que establece Plaza entre estos jardines, fundamentada en la documentación de archivo consultada, es a todas luces muy sugerente. No obstante, también plantea la existencia de un nexo entre estos jardines italianos y el de Sotofermoso, en Abadía, en la provincia de Cáceres, una propiedad vinculada al III duque de Alba, Fernando Álvarez de Toledo y Pimentel, y coetánea a los anteriores ejemplos napolitanos y florentinos.

En el segundo capítulo, «Los españoles en la creación del principado mediceo», Plaza se centra en la tarea realizada por Cosimo I para crear, implementar y desarrollar las nuevas estructuras de estado en el ducado florentino con un marcado enfoque absolutista. Para ello, según el caso, cambió, transformó o eliminó las estructuras políticas y administrativas de la época republicana. Aunque algunas reformas habían comenzado bajo el ducado de Alessandro de' Medici, la intervención de Cosimo consolidó las actuaciones ya acometidas y consiguió emprender otras que afectaban a áreas fundamentales del nuevo estado. Destacan especialmente las que desarrolló en los ámbitos de la defensa y de la educación, y la que redundó en la creación de una nueva sociedad áulica florentina. Sin embargo, en el estudio realizado por el autor se puede constatar que una de las empresas de mayor calado se realizó en el ámbito militar y de la defensa. Plaza señala que en los primeros años de andadura del ducado florentino los Medici se encontraban en una cierta posición de debilidad a pesar de tener la protección y el respaldo de Carlos V. En este sentido, el autor incide en la compleja situación y en la mutua desconfianza que se daba entre los Medici y la ciudad de Florencia, una desconfianza que había sido fraguada durante los años anteriores, con sendos exilios y con el asesinato de varios de sus miembros. Coincidimos con el autor en que sin esta desconfianza no podrían entenderse las dos decisiones relativas a la defensa: la construcción de la fortaleza de San Giovanni, adoptada por Alessandro de' Medici, y la creación por parte de Cosimo I de la Orden de Santo Stefano. En última instancia, ambas compartían unos fines similares: garantizar la seguridad personal del mandatario y, al mismo tiempo, ejercer un impacto disuasorio ante revueltas, tumultos y alzamientos de la población.

Otro episodio sobresaliente es la construcción del revestimiento pétreo del bastión de la fortaleza florentina a base de una decoración alternada de puntas y esferas que, según Plaza, remite a un modelo similar al empleado en el castillo de Manzanares el Real por parte de Juan Guas. El autor establece esta relación ante la ausencia de modelos coetáneos similares en Florencia y en Toscana, y habiendo observado que Lope Hurtado de Mendoza - que en 1536 comandó una guarnición de doscientos soldados españoles en la fortaleza de San Giovanni- es el hilo conector entre ambas fortalezas. En ese año de 1536, señala Plaza, estarían a punto de concluirse las obras en el recinto defensivo. Sin duda 
resulta muy llamativa esta interacción de la arquitectura tardogótica castellana en la arquitectura renacentista florentina, lo cual no hace sino subrayar que la circulación de personas e ideas a la que aludíamos con anterioridad se produjo en ambos sentidos.

También fue importante la creación de un cuerpo militar de élite: la mencionada Orden de Santo Stefano que, bajo la forma de orden de caballería, fue aprobada por el papa Pío IV -Giovanni Angelo de' Medici-en 1561. ${ }^{11}$ A pesar de que el objetivo fundacional era la defensa del Mediterráneo frente a la amenaza turca, se convirtió en un instrumento de control político y social del patriciado florentino. Plaza nos indica también cómo, bajo la dirección de Cosimo, la Orden se convirtió en una herramienta jurídica capaz de controlar el acceso al poder y al prestigio social tanto en Florencia como en la Toscana ducal. A su vez, el autor enfatiza en varios momentos que los primeros duques, en especial Cosimo I, favorecieron el ingreso de españoles en este cuerpo militar como un modo de reconocerles su importancia social y política en la ordenación del nuevo estado.

Otra gran reforma acometida por el duque fue la cultural, con una medida de gran calado: la reapertura del Studio di Pisa en 1543. Como señala el autor, la nueva puesta en funcionamiento de la universidad pisana fue, sin ningún género de dudas, un hito dentro de la política cultural medicea. En los comienzos de esta nueva etapa, el duque situó al salmantino Antonio de Castillo - persona de su máxima confianza- al frente de la institución y le encargó la reorganización del centro. Carlos Plaza apunta también que entre los motivos que podrían haber influido de forma decisiva en la reapertura del centro universitario se podría encontrar el papel que tradicionalmente habían jugado los Álvarez de Toledo como protectores de la Universidad de Salamanca, que estaba ligada en cierto modo a sus dominios. Durante este período también se implantó en Florencia la Compañía de Jesús a través de la fundación del Colegio de Toscana en 1552.

El otro pilar básico de la política de Cosimo fue la creación de un nuevo entorno áulico. A diferencia de otros estados italianos, como Nápoles, Ferrara, Mantua, Milán o Urbino, en la Florencia republicana no existía una corte, y por lo tanto la ordenación social de la ciudad estaba en manos de un patriciado urbano que ocupaba los cargos públicos y desarrollaba los valores y libertades cívicas. No obstante, a pesar del cambio de la forma de gobierno, en la etapa ducal, durante el mandato de Alessandro de' Medici y en los primeros años del gobierno de Cosimo I, no se desplegó un entorno cortesano alrededor de la figura del duque. Plaza nos indica que esta situación tuvo su punto de inflexión tras el matrimonio de Cosimo de Medici con Eleonora de Toledo, en 1539. La unión sirvió de catalizador para cambiar la realidad, que a partir de ahí se fundamentó en la experiencia de la familia Álvarez de Toledo, en general, y siguió el modelo del aparato cortesano asentado en torno a la figura del virrey Pedro de Toledo, en particular. Según

11. Statuti capitoli et constitutioni del Ordine de Caualieri di Santo Stephano fondato et dotato dal illust. et eccell. signor Cosimo Medici duca di Fiorenza et di Siena. Florencia: Lorenzo Torrentino, 1562. el autor, este nuevo escenario tendría dos consecuencias esenciales: la primera, que Cosimo se rodearía de gens nova, asunto que trataremos más adelante; y la segunda está relacionada con el ámbito arquitectónico, puesto que supuso el traslado de la residencia ducal del palacio Medici al palacio Vecchio, antigua sede del poder republicano, para lo cual hubo que acometer una serie de obras de adecuación, reestructuración y decoración, cuyo tema principal era la exaltación del poder absoluto de Cosimo I y de la familia Medici.

La primera parte de la obra de Plaza termina con el extenso tercer capítulo, «Arquitectura y política en la Florencia de Cosimo I». En primer lugar, el autor analiza la metacomitencia como una forma de política de intervención arquitectónica y urbana, basada en la lealtad de los subordinados unidos al metacomitente por una relación clientelar, para, de esta forma, desplegar un aparato iconográfico en la ciudad a partir de la arquitectura comisionada por ellos. Así, el metacomitente - en el caso que nos ocupa, Cosimo Iconsolida su imagen de gobernante y muestra los beneficios para quienes aceptan sin reservas su poder y lo sustentan como colaboradores de confianza. En este contexto es especialmente meritorio el esfuerzo de síntesis y sistematización evolutiva que realiza Plaza de la tipología arquitectónica del palacio florentino durante los siglos XV y XVI.

Uno de los puntos fuertes y más singulares de la obra, desde nuestro punto de vista, lo encontramos en la descripción de las labores de renovatio urbis emprendidas en Florencia por Cosimo. Esta renovación podría ser considerada como un programa de embellecimiento y modernización de la ciudad, marcado por actuaciones como la construcción de la Loggia del Mercato Nuovo, de los Uffizi y de las columnas de las plazas de Santa Trinità, San Marco y San Felice, a lo que habría que añadir las acciones de metacomitencia. Todo esto, a su vez, se desarrollaría bajo el paraguas legislativo de la normativa urbanística dictada por el duque: Legge Dell'Illustrissimo et Eccellentissimo S. Il S. Duca di Fiorenza, in comodo di quelli que volessimo edificare per tutto il suo stato, passata nel suo Consiglio de' 48 il 28 di Gennaio 1550 ab Incarn.

Es en este último punto donde encontramos una de las aportaciones más atractivas de la obra. El autor no se limita a realizar un análisis tipológico de las diferentes intervenciones urbanísticas, sino que las inscribe en el marco de la legislación florentina de la época. De esta forma, se puede llegar a percibir el verdadero calado de las reformas emprendidas, las cuales estaban a su vez en sintonía con el nuevo orden político del ducado mediceo. Carlos Plaza realiza un estudio comparado de las legislaciones urbanísticas de los otros territorios italianos que en aquellos momentos se encontraban en la órbita hispánica - Milán y Nápoles - con objeto de determinar cuáles eran los lugares comunes y las particularidades de cada uno de ellos, así como la relación existente con la forma de gobierno de cada territorio.

La segunda parte del texto se centra en el examen de la comitencia arquitectónica desplegada en la Florencia de los Medici a través de las actuaciones realizadas por Antonio Ramírez de Montalvo, Fabio Arrazola de Mondragón y Baltasar Suárez de la Concha, tres españoles que formaban parte de la llamada gens nova florentina. Anterior- 
mente nos hemos referido a la desconfianza mutua existente en la época ducal entre la familia Medici y el resto de la ciudad, y en especial respecto al resto del patriciado florentino que no era afín a las ideas e intereses de los Medici. Esta circunstancia propició que Cosimo I buscara personas de confianza que estuviesen apartadas de las intrigas que se desarrollaban en la ciudad, como era el caso de la pequeña nobleza toscana y de los españoles afincados en la ciudad del Arno.

Todos ellos formarían lo que se pasó a denominar gens nova, un conjunto de personas de procedencia social modesta o incluso humilde que debía su nueva posición privilegiada y su ascenso social al favor del duque. En el fondo, esta política se podría considerar como una maniobra de salvaguarda personal del mandatario. Así, Antonio Ramírez de Montalvo llegó a ser el favorito de Cosimo. Fabio Arrazola de Mondragón estuvo al cargo de su hijo Francesco y posteriormente le honró con el cargo de camarero mayor y con el hábito de la Orden de Santiago. Y, por último, Cosimo favoreció a Baltasar Suárez de la Concha, un comerciante con aspiraciones nobiliarias, que a pesar de no poseer un papel en la corte ducal disfrutó del favor de Ramírez de Montalvo, primero, y de Arrazola de Mondragón, después.

Carlos Plaza realiza una minuciosa labor de investigación para trazar una cartografía vital de cada uno de los tres personajes, indagando en sus orígenes hispánicos y en las posibles motivaciones que tuvieron para emprender un viaje solo de ida a Italia y terminar asentándose en Florencia. Asimismo analiza cómo y bajo qué circunstancias se produjo su ascenso social una vez se hallaban instalados en la ciudad toscana.

Llegados a este punto, Plaza estudia con detalle las residencias de cada uno de ellos, y reflexiona sobre el modo en que sus actuaciones intentaron acomodarse —en la medi- da de sus posibilidades económicas - a las características tipológicas del palacio florentino del Quinientos. En lo arquitectónico, estas actuaciones se desarrollaron según las disposiciones de la normativa urbanística vigente; y en lo decorativo, implementaron un programa iconográfico afín a la metacomitencia ducal.

Plaza consigue trazar y entretejer un sólido relato a lo largo de las dos partes en las que estructura esta obra. De hecho, ambas se encuentran tan íntimamente interconectadas y relacionadas que, en primer lugar, no hace sino poner de manifiesto la complejidad del tema abordado, y en segundo lugar, revela cómo ha sido capaz de llevar a cabo nuevas lecturas a partir de la documentación histórica conservada y de los estudios realizados hasta la fecha, junto con sus propias observaciones y experiencias sobre los objetos de estudio, y ofrecer de esta forma nuevas vías de análisis sobre la comitencia artística hispánica durante el período en el que Cosimo I de' Medici estuvo al frente de la ciudad. No obstante, y a pesar de quedar en un discreto segundo plano, el autor llega a configurar un vívido retrato psicológico del duque y, por extensión, de miembros muy destacados de la sociedad florentina y de su entorno personal, como es el caso de Antonio Ramírez de Montalvo, Fabio Arrazola de Mondragón, Baltasar Suárez de la Concha y, en menor medida, de su esposa, Eleonora de Toledo. Del mismo modo, pone de manifiesto los profundos cambios sociológicos e incluso mentales en los que se vio inmersa la sociedad florentina de esta época, que corren parejos a un proceso de creación y reafirmación de la identidad local como elemento fundamental en la consolidación del estado absolutista, que fue primero el Ducado de Florencia y posteriormente el Gran Ducado de Toscana. Esperamos que las sugerentes vías de investigación que Plaza plantea en su obra ofrezcan muy pronto interesantes frutos. 